$i$, as are their covariance matrices $\mathbf{V}_{i}$. Taking the $\mathbf{V}_{\mathrm{i}}$ as fixed, we assume the distribution of the $b_{i}$ to be

$$
\beta_{\mathrm{i}} \sim \mathrm{N}\left(\beta_{\mathrm{i}}, \mathbf{V}_{\mathrm{i}}\right)
$$

where

$$
\beta_{i} \sim N\left(\mu+x_{i}, \Sigma\right)
$$

that is, the distribution of the $\beta_{\mathrm{i}}$ depends on the year $\mathrm{i}$ by way of the parameter $x_{i}$. Assuming a linear trend in the parameter estimates we constrain $\chi_{i}$ such that

$$
x_{\mathrm{i}}=\mathrm{i} x
$$

Estimation and maximisation now proceed according to the computational details given by Dempster et $a l^{12}$ with the exception of $x$, an estimate of which may be achieved by maximum likelihood.

\section{Calculation of the profile}

All variable differences are standardised to a normal $\mathrm{N}(0,1)$ distribution using the parameter estimates from Scotland and from the hospital alone, together with the two standard errors of these estimates. Using figure 2 as an example, the parameter estimate (SE) for the variable associated with no antenatal care obtained from the Scottish model for death in the first week $(1984-7)$ was $2 \cdot 101(0 \cdot 386)$, while for hospital A these figures were $2 \cdot 534(1 \cdot 048)$. The $\mathrm{z}$ score for the difference in the parameter estimates (hospital A - Scotland) is then

$$
\begin{aligned}
\mathbf{z} & =(2 \cdot 534-2 \cdot 101) / \mathrm{V}\left(0 \cdot 386^{2}+1 \cdot 048^{2}\right) \\
& =0 \cdot 388
\end{aligned}
$$

Because the comparison is being made across eight variables, the confidence intervals are placed at $\pm 2 \cdot 734$, so that there is a probability of $0.025 / 8$ in each tail. The poin by this variable in figure 2 is therefore positioned $14 \%$ of the distance between the central vertical line (the mean for Scottish, representing zero difference) and the right hand edge of the shaded area $(95 \%$ simultaneous confidence interval).
1 Smith P. The use of performance indicators in the public sector. Fournal of the Royal Statistical Society A 1990;153:53-72.

2 Lowry S. Focus on performance indicators. BMf 1988;296:992-4

3 Lynch ML. Variation in hospital costs in Scotland. Glasgow: SPORU, University of Glasgow, 1990

+ Cole SK. Scottish maternity and neonatal records. In: Chalmers I, McIlwaine GM, eds. Perinatal audit and surveillance. London: Royal College of Obstetricians and Gynaecologists, 1980:39-51.

5 Brand R, Keirse MJNC. Using logistic regression in perinatal epidemiology: an introduction for clinical researchers. Part 1: basic concepts. Paediatric and Perinatal Epidemiology 1990;4:22-38.

6 Brand R. Using logistic regression in perinatal epidemiology: an introduction for clinical researchers. Part 2: the logistic regression equation. Paediutric and Perinat Epidemiology 1990:4:221:35.

7 Payne CD, ed. The GLIM system release 3.77. Oxford: Numerical Algorithms Group, 1985.

8 Bakketeig LS, Hoffman HJ, Oakley ART. Perinatal mortality. In: Bracken $\mathrm{MB}$, ed. Perinatal epidemiologv. New York and Oxford: Oxford University Press, 1984:99-151.

9 Pickering RM, Murray GD, Forbes JF Pre-term foetal life times in Scotland. Population Studies 1986;40:115-27.

10 Tyson J, Guzick D, Rosenfeld CR, Lasky R, Grant N, Jiminez J, et al. Prenatal care evaluation and cohort analyses. Pediatrics 1990;85:195-204.

11 Dempster AP, Laird NM, Rubin DB. Maximum likelihood from incomplete data via the EM algorithm (with discussion). Fournal of the Royal Statistical Society $B$ 1977;39:1-38.

12 Dempster AP, Rubin DB, Tsutakawa RK. Estimation in covariance components models. Fournal of the American Statistical Association 1981;76: $341-53$.

13 Wonnacott TH, Wonnacott RJ. Introductory statistics. 2nd ed. New York: Wiley, 1972.

14 Knox EG, Lancashire R, Armstrong EH. Perinatal mortality standards: construction and use of a health care performance indicator. $\mathcal{F}$ Epidemiol Community Health 1986;40:193-204.

15 Blumberg MS. Risk adjusting health care ourcomes: a methodological review. Medical Care Review 1986:43:351-93.

16 Williams RL, Cunningham GC, Norris FD, Tashiro M. Monitoring perinata mortality rates: California 1970 to 1976. Am J Obstet Gynecol 1980;136: $559-68$.

17 DesHarnais SI, Chesney JD, Wroblewski RT, Fleming ST, McMahon LF The risk-adjusted mortality index: a new measure of hospital performance. Med Care 1988:26:1129-45.

18 Stilwell J, Szczepura A, Mugford M. Factors affecting the outcome of maternity care. I. Relationship between staffing and perinatal deaths at the hospital of birth. $\mathcal{F}$ Epidemiol Community Health 1988;42:157-69. 19 Perinatal mortality rates-time for change? [editorial]. Lancet 1991;337:331

\title{
Randomised controlled trial comparing oral and intravenous rehydration therapy in children with diarrhoea
}

\author{
Angela Mackenzie, Graeme Barnes
}

Abstract

Objective-To determine the effectiveness of oral rehydration in children with moderate dehydration caused by gastroenteritis, and to compare the complications of oral and intravenous treatment.

Design-Randomised controlled trial.

Setting-Emergency department and infectious diseases ward in a large urban teaching hospital.

Patients - 111 children aged 3-36 months who had been previously healthy, had had diarrhoea for seven days or less, had clinical signs of dehydration, and were not in shock. Six children were withdrawn because the diagnosis was incorrect (four in oral group, two in intravenous group) and one (oral group) was withdrawn at her parents' request.

Interventions-Oral rehydration fluid was given

Department of

Gastroenterology, Royal

Children's Hospital,

Parkville, Victoria 3052,

Australia

Angela Mackenzie, FRACP, research fellow

Graeme Barnes, MD, director

of gastroenterology

Correspondence to:

Dr Angela Mackenzie,

20 Manningham Street,

Parkville, Victoria 3052,

Australia.

BMf 1991;303:393-6 children $(52 \%)$ in the oral group and 11 of $50(22 \%)$ in the intravenous group vomited during rehydration. There was no significant difference between the two treatment groups in the number of stools passed during rehydration $(p=0.09)$. None of the children had serious complications of treatment.

Conclusion-Rehydration by mouth or nasogastric tube is a safe and effective treatment for moderately dehydrated children with gastroenteritis.

\section{Introduction}

Oral rehydration is underused in developed countries, usually being given only for maintenance or to correct mild dehydration. Two factors contribute to the overuse of intravenous fluid: firstly, the degree of dehydration is consistently overestimated in children in developed countries ${ }^{1}$ and, secondly, it is widely believed that children with anything more than mild dehydration should be rehydrated with intravenous fluid $^{2}$ despite much evidence from developing countries that oral rehydration is safe and effective treatment even for severe dehydration (provided that the patient is not in shock).

Few controlled trials have been performed in developed countries to test whether oral rehydration is as successful as the more expensive and complicated intravenous therapy. ${ }^{47}$ In addition many doctors believe that oral rehydration is more labour intensive. ${ }^{8}$ These two factors have contributed to the reluctance of doctors in developed countries to use oral rehydration.

To assess the effectiveness of oral rehydration and to compare the complications of oral and intravenous 
treatment we performed a randomised controlled trial of oral rehydration in children admitted to hospital in Australia. Because of the detrimental effects of admitting children to hospital and the shortage of hospital beds one aim was to determine whether dehydration could be corrected orally over six hours, so that dehydrated children could be managed as outpatients or short stay inpatients.

\section{Patients and methods}

Children aged 3-36 months who presented to the emergency department during June 1986 to July 1988 with acute gastroenteritis and moderate dehydration were eligible for the study. Acute gastroenteritis was defined as diarrhoea of sudden onset that had been present for seven days or less, with or without vomiting, when there was no other cause identified. Dehydration was assessed with the Royal Children's Hospital guidelines: the presence of any one of depressed fontanelle, diminished skin turgor, sunken eyes, dry mucous membranes, peripheral circulatory failure, oliguria, or recent weight loss was taken to imply dehydration of $5 \%$ or more. Obvious signs were taken to mean $7-10 \%$ dehydration and circulatory failure to mean dehydration of more than $10 \% .{ }^{9}{ }^{10}$ Children were enrolled in the study by AM or the admitting officer after verbal consent was obtained from the parent(s). Children with chronic illness were excluded.

Randomisation was performed by using sealed envelopes, in blocks of two, stratified by age (3-15 months and 16-36 months). Children received either oral or intravenous treatment. Fluid orders were written according to tables based on fluid deficit, maintenance requirements, and ongoing losses. An hourly rate was calculated in advance for each weight to standardise treatments: $100 \mathrm{ml} / \mathrm{kg} /$ day for maintenance requirements and $50 \mathrm{ml} / \mathrm{kg} /$ day for ongoing losses. Breast feeding was continued. No solids were given until the children were rehydrated.

Oral therapy consisted of an unflavoured glucoseelectrolyte solution containing sodium $50 \mathrm{mmol} / \mathrm{l}$, potassium $20 \mathrm{mmol} / \mathrm{l}$, chloride $40 \mathrm{mmol} / \mathrm{l}$, citrate $10 \mathrm{mmol} / \mathrm{l}$, and glucose $111 \mathrm{mmol} / \mathrm{l}$ (2\% glucose). The fluid deficit was replaced over six hours. It was recommended that fluids be given initially in frequent small sips. Oral rehydration fluids were given by nasogastric infusion when children were tired or if they refused to drink.

Intravenous therapy was $4 \%$ dextrose in $0 \cdot 18 \%$ physiological saline with potassium chloride $20 \mathrm{mmol} / \mathrm{l}$ added. The deficit was replaced over 24 hours. The drip site was examined hourly and any redness or swelling recorded. Residents used their discretion about whether to replace a drip if it became dislodged from the vein within 24 hours. Children in the intravenous group were allowed to drink oral rehydration solution.

The children were examined at the start of treatment and after six and 24 hours. Resident medical officers assessed the level of hydration; clinical signs were not recorded in some children at six hours because the doctor was not available. Nursing staff recorded the child's vital signs and naked weight. Accurate weighing was important because the degree of dehydration was calculated by subtracting the child's weight before rehydration from the weight measured on the same scales after rehydration. Investigations included serum sodium, potassium, and urea concentrations and capillary acid-base state. Faeces were sent for routine bacterial and viral diagnostic studies. The number of times that the children vomited and passed stools and their fluid intake were recorded. Children were reweighed daily until discharge.
Oral rehydration was said to have failed if the independent consultant paediatric gastroenterologist thought that persistent vomiting was severe enough to prevent rehydration or there was weight loss of $2 \%$ after admission or impending circulatory failure. Previous studies suggest a failure rate of about $5 \%$ with oral rehydration, ${ }^{3}$ and the failure rate with intravenous therapy is $0 \%$. We wanted to obtain an estimate of the maximum failure rate with oral rehydration (a one sided test); to be $95 \%$ sure that there would be no more than a $5 \%$ difference between the failure rate in our study and the true failure rate with oral rehydration 52 children were required in the orally rehydrated group." An equal number of children was included in the intravenous group to allow for comparison of the complications of oral and intravenous treatment and to reduce the chance of selection bias. Continuous variables were compared by the Mann-Whitney U test and categorical variables by Fisher's exact test. The study was approved by the Royal Children's Hospital Ethics in Human Research Committee.

\section{Results}

We enrolled 111 children in the study, of whom 57 were randomised to oral rehydration and 54 to intravenous rehydration. Seven children were excluded from the analysis, two in the intravenous group (both had intussusception) and five in the oral group (two had septicaemia, one had a urinary tract infection, one had duodenal ulcer complicating gastroenteritis, and one was withdrawn from the study at her parents' request). After exclusion of the seven children there were 52 children in each treatment group; the two groups had similar characteristics (table I). All 111 children recovered completely.

TABLE I-Characteristics of children admitted to hospital with diarrhoea and randomised to receive oral or intravenous treatment. Values are medians (interquartile ranges) unless stated otherwise

\begin{tabular}{lll}
\hline & \multicolumn{1}{c}{$\begin{array}{c}\text { Oral group } \\
(\mathrm{n}=52)^{\star}\end{array}$} & $\begin{array}{c}\text { Intravenous group } \\
(\mathrm{n}=52)^{\star}\end{array}$ \\
\hline Age (months) & $19 \cdot 5(12 \cdot 0$ to $24 \cdot 0)$ & $20 \cdot 5(14 \cdot 0$ to $26 \cdot 0)$ \\
No aged 3-15 months & 19 & 14 \\
No aged 16-36 months & 33 & 38 \\
Male:female & $34: 18$ & $30: 22$ \\
No (\%) with history of vomiting & $45 / 52(87)$ & $49 / 52(94)$ \\
Days of diarrhoea & $3 \cdot 0(2 \cdot 0$ to $4 \cdot 0)$ & $2 \cdot 5(2 \cdot 0$ to $4 \cdot 0)$ \\
Temperature $\left({ }^{\circ} \mathrm{C}\right)$ & $37 \cdot 3(36 \cdot 9$ to $38 \cdot 0)$ & $37 \cdot 2(36 \cdot 5$ to $37 \cdot 8)$ \\
No(\%) who had had antibiotics & $18 / 52(35)$ & $10 / 52(19)$ \\
No(\%) breast fed & $0 / 52$ & $5 / 52(10)$ \\
Pulse rate (beats/min) & $135(120$ to 150$)$ & $130(116$ to 140$)$ \\
Systolic blood pressure (mm Hg) & $102(90$ to 110$)$ & $105(93$ to 111$)$ \\
No(\%) with rotavirus infection & $27 / 46(59)$ & $32 / 45(71)$ \\
No(\%) with estimated dehydration: & $31 / 52(60)$ & $36 / 52(69)$ \\
$\quad 5-6 \%$ & $21 / 52(40)$ & $16 / 52(31)$ \\
$7-10 \%$ & & \\
No(\%) with 5-10\% dehydration by & & \\
weight gain & $22 / 46(48)$ & $17 / 47(36)$ \\
\hline
\end{tabular}

No significant differences between the two groups in any of the variables. $\star$ For some variables data were not available on all children.

Oral rehydration failed in two of 52 children, a failure rate of $3.8 \%$ with an exact one sided upper $95 \%$ confidence limit of $11 \cdot 6 \% .{ }^{12}$ Both children were thirsty but continued to vomit: one lost a further $1.8 \%$ of her body weight after six hours of oral treatment and became more uraemic and acidotic; the other was not reweighed, but he was in negative fluid balance of $150 \mathrm{ml}$ four hours after admission and intravenous fluids were then started. Neither child received nasogastric fluids. There were no failures in the children treated intravenously.

Because the protocol called for more rapid rehydration in the oral group, these children received significantly more fluid in the first six hours $(p<0.01)$ (table II). Children who were rehydrated orally vomited more often: 26 of 50 children (52\%) in the oral group and 11 of $50(22 \%)$ in the intravenous group vomited 
TABLE II-Comparison of children receiving oral and intravenou treatment during 24 hours treatment after admission. Values are medians (interquartile ranges)

\begin{tabular}{|c|c|c|}
\hline & $\begin{array}{l}\text { Oral group } \\
(n=52)^{\star} t\end{array}$ & $\begin{array}{l}\text { Intravenous group } \\
\quad(n=52)^{\star} \dagger\end{array}$ \\
\hline \multicolumn{3}{|l|}{ No of vomits: } \\
\hline $0-6$ & $1(0$ to 2$)$ & $0(0 \text { to } 0)^{\star \star}$ \\
\hline $0-24$ & $1(0$ to 2$)$ & $0(0 \text { to } 0)^{\star \star}$ \\
\hline \multicolumn{3}{|l|}{ No of times stools passed: } \\
\hline $0-6$ & $1(0$ to 3$)$ & $0(0 \text { to } 2)^{\star}$ \\
\hline $0-24$ & $5(1$ to 10$)$ & $4(1$ to 6$)$ \\
\hline \multicolumn{3}{|l|}{ Fluid intake $(\mathrm{ml} / \mathrm{kg})$ : } \\
\hline $0-6$ & $63(41$ to 81$)$ & $47(39 \text { to } 57)^{\star}$ \\
\hline $0-24$ & 94 (79 to 142$)$ & 122 (90 to 147$)$ \\
\hline \multicolumn{3}{|l|}{ Serum sodium $(\mathrm{mmol} / \mathrm{l})$ : } \\
\hline 0 & $138(135$ to 141$)$ & $138(136$ to 140$)$ \\
\hline 6 & 136 (133 to 137$)$ & 135 (134 to 137$)$ \\
\hline 24 & 137 (135 to 139$)$ & $138(136$ to 140$)$ \\
\hline \multicolumn{3}{|c|}{ Serum potassium (mmoll): } \\
\hline 0 & $4 \cdot 2(3.8$ to 4.5$)$ & $4.4(3.8$ to 4.6$)$ \\
\hline 6 & $4.4(3.8$ to 5.0$)$ & $4.5(3.9$ to 5.0$)$ \\
\hline 24 & $4 \cdot 6(4 \cdot 2$ to 4.9$)$ & $4 \cdot 6(4 \cdot 3$ to $5 \cdot 0)$ \\
\hline \multicolumn{3}{|l|}{ Serum urea $(\mathrm{mmol} / \mathrm{l})$ : } \\
\hline 0 & $5.9(3.9$ to $7 \cdot 3)$ & $6 \cdot 4(4 \cdot 2$ to $8 \cdot 2)$ \\
\hline 6 & $4.8(2.9$ to 5.8$)$ & $3.8(2.6$ to 5.5$)$ \\
\hline 24 & $2.7(1.8$ to 3.9$)$ & $1.7(1.0 \text { to } 2.8)^{\star \star}$ \\
\hline \multicolumn{3}{|l|}{$\mathrm{pH}:$} \\
\hline 0 & $7.37(7.34$ to 7.42$)$ & $7.37(7.33$ to 7.41$)$ \\
\hline 6 & $7 \cdot 40(7 \cdot 38$ to $7 \cdot 43)$ & $7 \cdot 40(7 \cdot 38$ to $7 \cdot 45)$ \\
\hline 24 & $7 \cdot 45(7 \cdot 42$ to $7 \cdot 46)$ & $7.45(7.43$ to 7.47$)$ \\
\hline \multicolumn{3}{|l|}{ Base excess: } \\
\hline 0 & $-7 \cdot 4(-10 \cdot 0$ to $-5 \cdot 7)$ & $-7 \cdot 1(-9 \cdot 2$ to $-4 \cdot 4)$ \\
\hline 6 & $-4 \cdot 3(-7 \cdot 7$ to $-2 \cdot 3)$ & $-5.0(-5.9$ to -2.3$)$ \\
\hline 24 & $-0.7(-3.4$ to 1.3$)$ & $-2.0(-3.9$ to 0.1$)$ \\
\hline Weight at $24 \mathrm{~h}(\mathrm{~kg})$. & $11 \cdot 2(9 \cdot 5$ to $12 \cdot 5)$ & $11 \cdot 3(9 \cdot 8$ to $12 \cdot 3)$ \\
\hline $\begin{array}{l}\text { Length of hospital stay } \\
\text { (days) }\end{array}$ & $2 \cdot 0(2 \cdot 0$ to $4 \cdot 0)$ & $2 \cdot 0(2 \cdot 0$ to $3 \cdot 0)$ \\
\hline
\end{tabular}

${ }^{\star}=\mathrm{p}<0.05 ;{ }^{\star \star} \mathrm{p}=<0.01$ (Mann-Whitney U test).

†For some variables data were not available on all children.

during rehydration $(p<0.01)$. Only 10 children in the oral group vomited more than three times. During the 24 hours that the children were studied there was little difference between the two treatment groups in the number of times stools were passed $(p=0.09): 26$ of 50 children (52\%) in the oral group and 21 of $50(42 \%)$ in the intravenous group passed stools more than four times.

On clinical assessment six hours after admission, 29 of 49 children (59\%) in the oral group and 34 of 46 (74\%) in the intravenous group were either rehydrated or only mildly dehydrated. Ninety seven of 101 children were clinically assessed as being rehydrated 24 hours after admission; two children in each treatment group took 48 hours to rehydrate. In the oral group two children became dehydrated again after initially improving, but neither required intravenous fluids. Subtraction of the weight after rehydration from the weight six hours after treatment had started showed that 47 of 51 children $(92 \%)$ in the oral group were less than $4 \%$ dehydrated and that $20(39 \%)$ were completely rehydrated (fig).

The serum sodium and potassium concentrations and capillary acid-base state were similar for the two groups at six and 24 hours. Urea concentrations were significantly lower in the intravenously rehydrated group than in the oral group at 24 hours $(p<0.01)$, but the mean concentrations for both groups were well within the normal range and the difference was not clinically important. Acidosis was corrected at the same rate in both treatment groups, even though children who were rehydrated intravenously did not routinely receive bicarbonate (table II). No child became hypernatraemic during treatment; two children receiving oral rehydration and one receiving intravenous rehydration had serum sodium concentrations over $150 \mathrm{mmol} / \mathrm{l}$ on admission, but the concentration corrected in all three with rehydration. The sodium concentration of three children in the oral group fell below $130 \mathrm{mmol} / \mathrm{l}$ after treatment for six hours; the concentrations returned to normal by 24 hours.
Seven children developed obvious redness or swelling at the drip site. Five children in the intravenous group and one in the oral group developed periorbital oedema $(p=0 \cdot 2)$. Fourteen of the children in the oral group received some of their fluids by nasogastric infusion; the nasogastric tube seemed to exacerbate vomiting in one child.

\section{Discussion}

The teaching in Australia and other developed countries has been to treat a child with gastroenteritis who has signs of dehydration ${ }^{10}$ or vomiting ${ }^{13}$ with intravenous fluid. Our study shows that oral rehydration can replace intravenous rehydration in children who are dehydrated but not in shock even if they are vomiting. Forty five children (87\%) in the oral group had a history of vomiting, yet most tolerated oral or nasogastric fluids well.

There was more vomiting and a trend towards a higher stool output in the oral group than in the intravenous group, but neither of these differences was clinically important. The increased frequency of vomiting in the oral group may have been unpleasant for some children, but this has to be weighed against the fact that rapid oral rehydration may mean that many children do not have to be admitted to hospital A recent study has shown that stool output may be reduced by using a solution containing rice-syrup solids rather than glucose. ${ }^{14} \mathrm{~A}$ failure rate of $3 \cdot 8 \%$ with an upper $95 \%$ confidence limit of $11.6 \%$ means that at least $85 \%$ of children who would previously have received intravenous treatment can be treated orally. The failure rate may have been even lower if fluid had been given by nasogastric tube to the two children who could not be rehydrated orally.

Problems with this study include the facts that it could not be a double blind trial and that failure of oral treatment was not a clear end point. Nevertheless, the decision that oral therapy had failed was made by an independent consultant and not by the chief investigator. Another problem was that over half the children who were assessed clinically as $5-10 \%$ dehydrated at the time of admission were found not to have been moderately dehydrated according to later weight gain, which is the best objective measure available. This tendency to overestimate dehydration meant that some children who were not dehydrated were given intra-

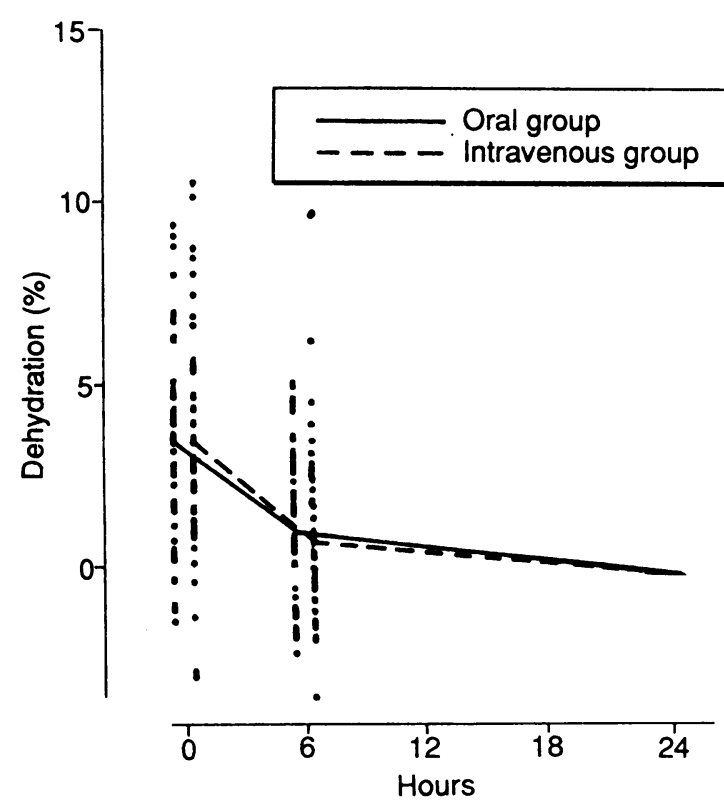

Percentage dehydration on admission to hospital and after six hours in children with diarrhoea. 
venous fluids. Routine use of oral rehydration would help prevent such overtreatment.

Oral rehydration was at least as good as intravenous treatment as judged by biochemical tests. Electrolyte and acid-base measurements do not need to be made routinely in children with dehydration caused by acute gastroenteritis if they are treated with an oral rehydration solution similar to the one we used; this reduces costs and avoids the trauma of collecting blood. From the child's point of view, oral rehydration is preferable to intravenous treatment because it causes less physical and emotional pain. Some children might find a nasogastric tube uncomfortable and distressing, but administration of fluids by this method may add to the safety of oral rehydration therapy by ensuring that the child receives an adequate volume of fluid.

There is a widespread unsubstantiated belief that oral rehydration is more time consuming than intravenous therapy, ${ }^{815}$ which may partly explain why oral rehydration is still underused. In our study the children either drank at an adequate rate or had a nasogastric tube inserted, which limited the amount of time spent administering fluids. Two thirds of the children had no clinical signs of dehydration within six hours, so most children could be managed as short stay inpatients or as outpatients provided that there was provision for appropriate review.

Entrenched attitudes to management are not easy to overcome. The turning point in this study occurred when a doctor personally supervised the rehydration of a moderately dehydrated infant over the first six hours. The staff were so impressed with the success of oral rehydration in this one child that their attitude to treatment changed, and it became necessary to put a good case for using an intravenous line. Education of staff is crucial if developed countries are to catch up with advances in the developing world.

It is time for staff in the teaching hospitals in developed countries to become familiar with oral rehydration therapy, which includes early feeding, ${ }^{16}$ and to use it in all but the most severe cases of dehydration. In the long term, oral rehydration solutions would become more widely used in the community, and this would greatly reduce the incidence of dehydration and decrease the need for children to be admitted to hospital.

We thank the many residents and nurses in the emergency department and infectious diseases ward for their cooperation and Dr Frank Shann for his constructive criticism and statistical advice.

1 Mackenzie A, Barnes G, Shann F. Clinical signs of dehydration in children. Lancet 1989;ii:605-7.

2 Walker-Smith JA. Advances in oral rehydration. Drugs 1988;36 (suppl 4): 99-108.

3 Ecckels R, ed. Annotated bibliography on diarrhoeal diseases: review articles and selective studies. Dhaka: International Centre for Diarrhoeal Disease Research, Bangladesh, 1989. (Specialised bibliography series No 13.)

Santosham M, Daums RS, Dillman L, et al. Oral rehydration therapy of infantile diarrhea. $N$ Engl f Med 1982;306:1070-6.

5 Tamer AM Friedman LB, Maxwell SRW, Cynamon HA, Perex HN, Cleveland WW. Oral rehydration of infants in a large urban US medical Cleveland WW. Oral rehydration

6 Listernick R, Zieserl E, Davis AT. Outpatient oral rehydration in the United States. Am f Dis Child 1986;140:211-5.

7 Vesikari T, Isolauri E, Baer M. A comparative trial of rapid oral and intravenous rehydration in acute diarrhoea. Acta Pediatr Scand 1987;76:

8 Avery ME, Snyder JD. Oral therapy for acute diarrhea: the underused simple solution. N Engl f Med 1990;323:891-4.

Royal Children's Hospital. Residents handbook. Melbourne: Royal Children's Hospital, 1983:3.2.

10 Robinson MJ, ed. Practical paediatrics. Melbourne: Churchill Livingstone, 1986:482-90.

11 Colton T. Statistics in medicine. Boston: Little Brown, 1974:162.

12 Armitage P, Berry G. Statistical methods in medical research. 2nd ed. Oxford: Blackwell, 1987:119-20.

13 Behrman RE, Vaughan VC, eds. Nelson textbook of pediatrics. 13th ed. Philadelphia: W B Saunders, 1987:197.

14 Pizarro D, Posada G, Sandi L, Moran JR. Rice-based oral electrolyte solution for the management of infantile diarrhea. N Engl 7 Med 1991:324:517-21.

15 Candy CE. Recent advances in the care of children with acute diarrhoea: givin responsibility to the nurse and parents. F Adv Nurs 1987;12:95-9.

16 Santosham M, Brown KH, Sack BR. Oral rehydration therapy and dietary therapy for acute childhood diarrhea. Pediatr Rev 1987;8:273-8.
thes

(Accepled 30 May 199I)
Royal Liverpool Children's Hospital (Alder Hey), Liverpool L12 2AP Matthew van Miert, FCANAES, registrar in anaesthesia

Roger E Thornington, FFA(SA), consultant anaesthetist Dick van Velzen, PHD, professor of fetal and infant pathology

Correspondence to:

Dr Thornington.

BMF 1991;303:396-7

\section{Cardiac arrest after massive acute fat embolism}

\author{
Matthew van Miert, Roger E Thornington, \\ Dick van Velzen
}

Cardiac arrest under anaesthesia has been reported after both venous and air embolism. We report a case in which a fatal cardiac arrest occurred owing to acute massive fat embolism after closed manipulation of the hips.

\section{Case report}

A 12 year old boy with severe cerebral palsy was admitted for correction of his kyphoscoliosis. He was tetraplegic with contractures of all limbs. Previous orthopaedic surgery included release of the external rotator muscles of the hips through a posterior approach and a spinal fusion. Both anaesthetic procedures had been uneventful. He was premedicated, anaesthetised, intubated, and ventilated. We then established that both hips had fixed extension deformities, which, with the loss of spinal flexion, would prevent him sitting in a wheelchair. The hips were uneventfully flexed to $90^{\circ}$ under anaesthesia.

The patient developed a nodal bradycardia and became cyanosed with a weak carotid pulse. External cardiac massage was started and he was given $100 \%$ oxygen and atropine and adrenaline, but he remained cyanosed and became asystolic. Massage produced palpable femoral pulses, but no expired carbon dioxide was detected, implying that no gas was being exchanged in his lungs. We provisionally diagnosed massive pulmonary or fat embolism. $x$ Ray films of his hips and chest showed no abnormalities. We stopped resuscitation after $\mathbf{4 5}$ minutes as the patient remained asystolic and his pupils were fixed and dilated.

A massive pulmonary fat embolus was found at necropsy. Large amounts of friable fat and minute fragments of bone were present in the pulmonary arteries. This had resulted in acute right heart failure. Both femurs were very osteoporotic with bilateral fractures of the femoral neck and bone marrow in the cavities of both hip joints. In the left hip this bone marrow was under such pressure that it was forcibly extruded after the joint capsule was incised.

\section{Comment}

After traumatic fractures of long bones embolisation of fat from the bone marrow into the venous system produces the fat embolism syndrome. The main diagnostic features are respiratory and cerebral failure and a petechial rash. ${ }^{1}$ In this patient the massive amount of fat from the bone marrow entering the venous circulation caused acute right heart failure and circulatory arrest. This is known as the fulminant fat embolism syndrome. ${ }^{2}$

Massive fat embolism has not been described after manipulation of an intact limb. A similar collapse 